\title{
Identification of the Effects of Fire-Wave Propagation through the Power Unit's Boiler Island
}

\author{
Michał Paduchowicz * and Artur Górski
}

\author{
Department of Machine and Vehicle Design and Research, Faculty of Mechanical Engineering, \\ Wroclaw University of Science and Technology, 27 Wybrzeże Wyspiańskiego, 50-370 Wrocław, Poland; \\ artur.gorski@pwr.edu.pl \\ * Correspondence: michal.paduchowicz@pwr.edu.pl; Tel.: +48-71-320-39-08
}

\section{check for} updates

Citation: Paduchowicz, M.; Górski, A. Identification of the Effects of Fire-Wave Propagation through the Power Unit's Boiler Island. Energies 2021, 14, 1231. https://doi.org/ $10.3390 /$ en14051231

Received: 2 December 2020

Accepted: 10 February 2021

Published: 24 February 2021

Publisher's Note: MDPI stays neutral with regard to jurisdictional claims in published maps and institutional affiliations.

Copyright: (C) 2021 by the authors. Licensee MDPI, Basel, Switzerland. This article is an open access article distributed under the terms and conditions of the Creative Commons Attribution (CC BY) license (https:/ / creativecommons.org/licenses/by/ $4.0 /)$.

\begin{abstract}
The article presents the results obtained during the inspection of the load-bearing structure of a power unit that suffered from fire. The inspection, consisting in the assessment of both the structure's technical condition and durability of welded joints, was performed on seven height levels of the power unit. The vibration spectrum of the unit's steel structure was analyzed, and frequency characteristics were, thus, obtained for individual measurement levels. Thermal vision measurements were also performed in the unit's all connection points to check for possible unsealing of some elements in the boiler island of the inspected power unit. The next stage consisted of performing strength calculations of the steel structure with a goal to estimate the structure's stress state. The conclusions contain suggestions for modernization of welded joints in order to maintain the power unit's design strength.
\end{abstract}

Keywords: power boilers; the load-bearing structures; damage assessment; fires; tanks

\section{Introduction}

The article addresses the problem presented in many other publications on the spread of fires in industrial installations [1]. As the results of the article [2] show, the main causes of fires in such places as coal-fired power plants, where hard coal are used, are explosive works, self-heating as well as friction and impact. In this study, an attempt was made to verify the causes of the fire and to verify the effects of the passage of the fire wave through the area of power units covered with brown coal together with biomass. The thesis was put forward that the combustion of these two fuels is dangerous at the same time due to the self-heating of biomass, which may lead to its spontaneous ignition. This, in turn, taking into account the ease and speed of coal dust (brown coal is crushed into a dust fraction and dried at the same time before being fed to the combustion chamber), may affect the intensity of combustion, which in turn may cause an explosion at high concentration of this element. If we take into account the fact that in the vicinity of fluidized bed power units, there are large amounts of coal dust (among others on communication elements such as platforms, barriers), this will largely help to spread the fire wave within the boiler installations.

Within a power unit's boiler island, a passing fire wave affected the unit's second pass (convection chamber), the cyclone, ash removal system, air-supply system, etc. The point of origin and the path of the fire wave are shown in Figure 1 [3]. References should be numbered in order of appearance and indicated by a numeral or numerals in square brackets, e.g., see the end of the document for further details on references $[4,5]$.

The fire was initiated in the conveyor belt gallery situated in the coal and biomass supply line of power unit A. The fire wave later traveled through communication lines located between the power units and approached further generating units. The propagation of the fire wave necessitated evaluation of the degradation and damage caused to particular elements of the power units. The tests and measurements in this case were complex and consisted of [6]: 
- Geometric measurements of the power unit's main components: load-bearing structure, second pass chamber, cyclone, ash removal system, air ducts, accessory elements, etc.;

- Identification of deviations from technical documentation and measurement results prior to the fire;

- Non-destructive measurements of accessible welded joints in the power unit's main components, load-bearing structure, second pass convection chamber, cyclone, ash removal system, air ducts, and auxiliary elements, etc., in order to find potential material discontinuities;

- Evaluation of damage levels for selected spots of the investigated power unit's elements after the fire;

- Weld quality tests (continuity tests) regarding geometric welding imperfections [7];

- Measurement of vibration levels for the power unit's load-bearing structure in order to identify vibration amplitude;

- Thermal imaging measurements of temperature distribution on particular elements of the inspected power unit;

- $\quad$ Noise level measurements, in particular, selected spots of the power unit;

- Development of necessary selected computational models for the power unit's components that allow for computer simulations of the impact of fire wave on the structure's shape. Numerical analysis of the likelihood that load-bearing structure, furnace chamber and second pass, cyclone, ash removal system, air ducts, auxiliary elements, etc., suffered from permanent deformations caused by fire wave.

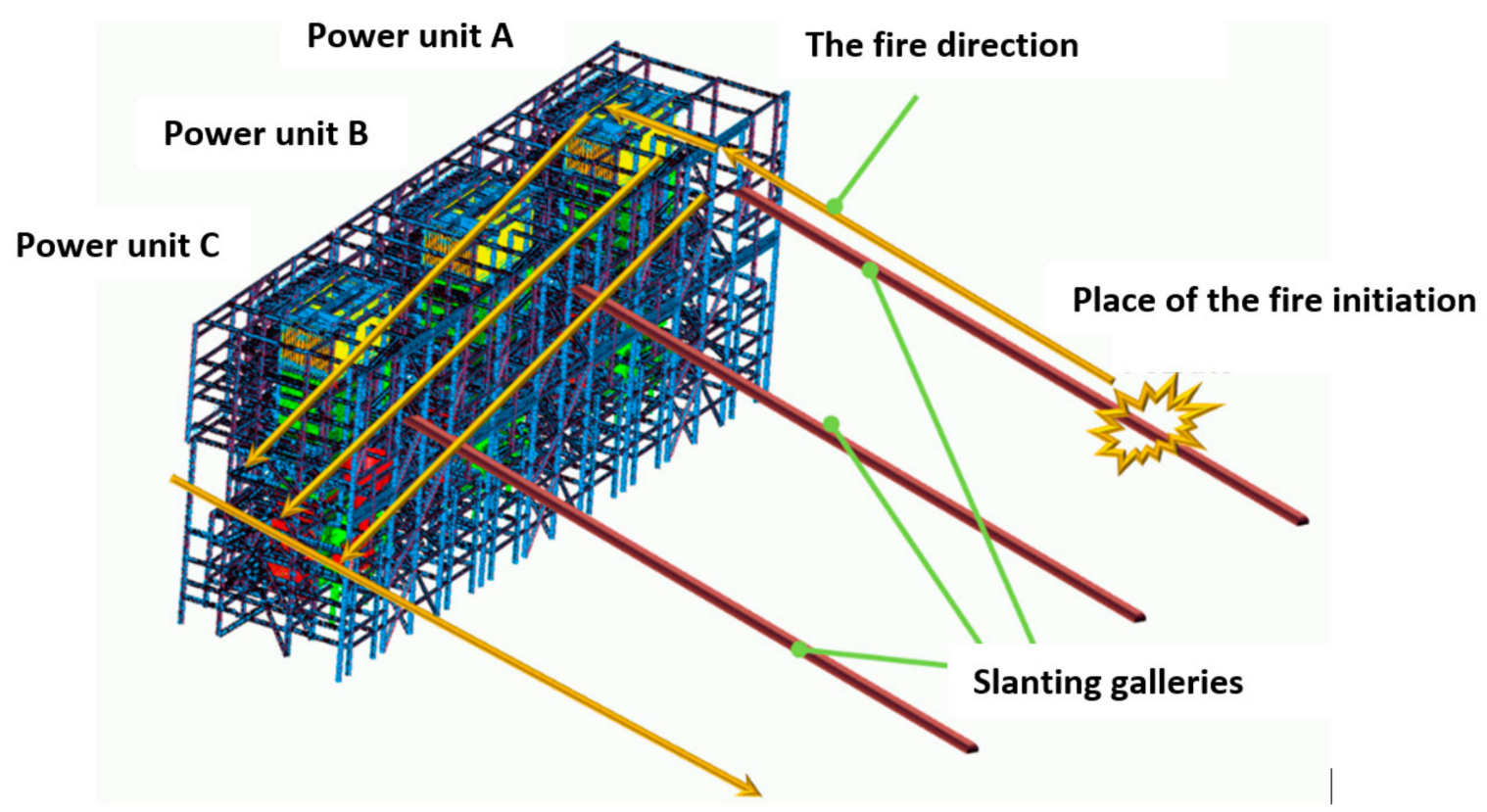

Figure 1. The fire's point of origin and way through the power units.

Determination of the actual state of effort of structural elements subjected to thermal loads is crucial in the assessment of the technical condition of power unit elements. The literature presents many practical methods; however, in the case of such a complex structure as a power unit with the entire installation of water, steam, coal, lime and air, its own methodology was proposed, consisting in the integration of numerical and experimental methods. The main assumption of the methodology is the dependence of the value of reduced stresses on temperature (1).

$$
\sigma_{i}^{(T)}=-\frac{E \beta\left(T-T_{0}\right)}{1-2 v}
$$


where the temperature field is described (2):

$$
\frac{\partial}{\partial x_{i}}\left[\lambda_{i j} \frac{\partial T}{\partial X_{j}}\right]+q_{V}=\rho c \frac{\partial T}{\partial t}
$$

- $\quad$ - T-medium temperature;

- $\quad \lambda_{i j}$-matrix of thermal conductivity coefficients;

- $\rho$-density;

- $\quad q_{v}$-heat generated in the medium;

- $\quad c$-pecific heat;

- $\quad t$-time.

The research on the causes of the fire was based on simultaneous thermal and structural analyses, which are presented in the diagram below (Figure 2).

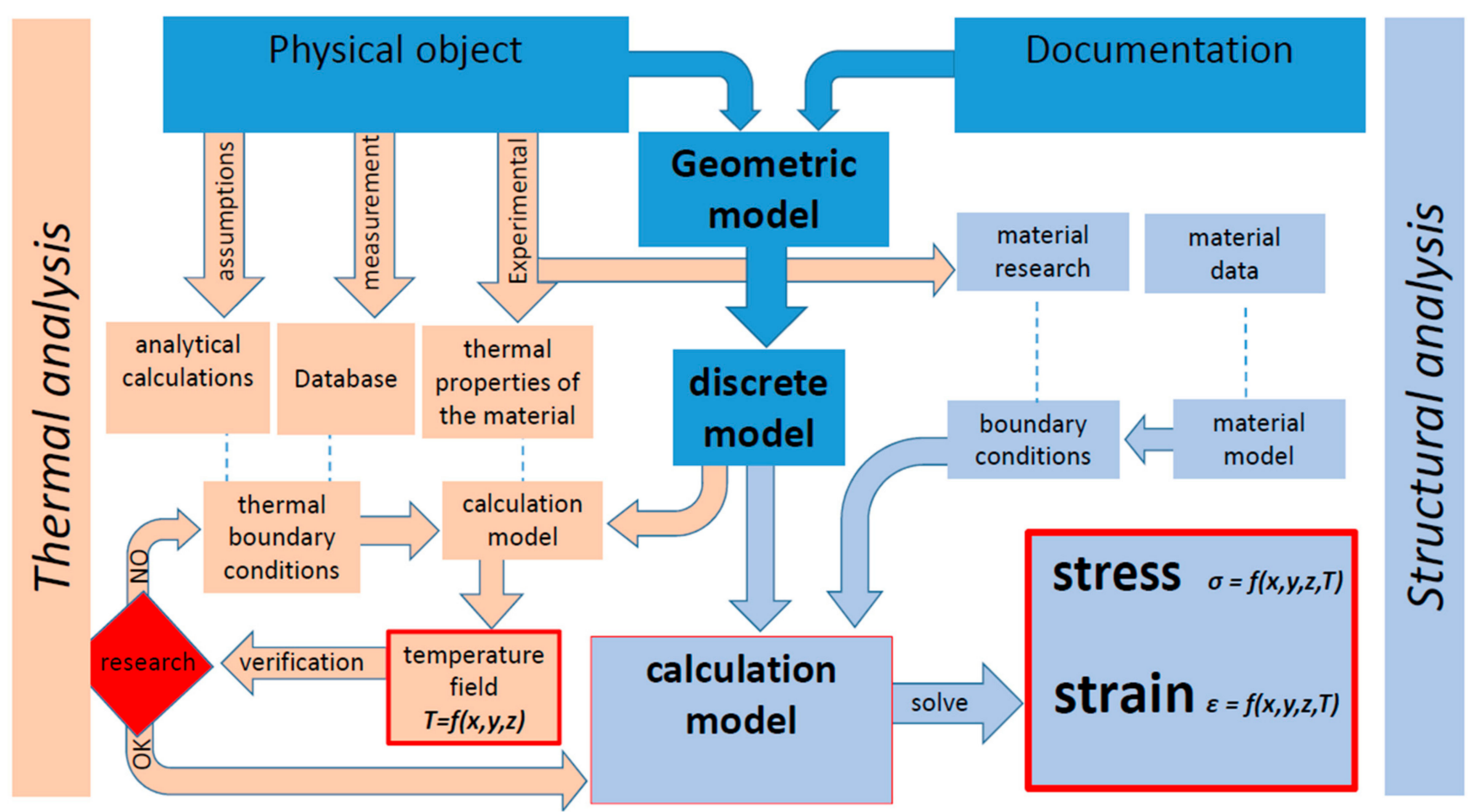

Figure 2. Scheme of tests carried out on the power unit where the fire occurred.

The research scheme presented in the figure above refers to the numerical analysis performed using the finite element method. First, the thermal analysis of the power device model is carried out, and then, using the obtained spatial temperature field and mechanical loads, the complex state of stress of this structure is determined.

\section{Operating Parameters of Fluidized Bed Power Unit}

For the past few years, electric energy producers have been obliged by EU legal regulations to cofire biomass with coal in conventional power units. This requirement compromises fire safety within the area of energy facilities in operation. One of the greatest threats is coal autoignition resulting from its coming into contact with biomass of typically high temperature. The above case was the hypothetical reason behind the ignition of fire in one of the biomass supply galleries in the analyzed power unit [8].

Apart from that, the use of biomass as one of the ingredients included in the fuel supplied to the boilers in conventional power units greatly influences operating conditions of the whole boiler system. The most frequent problem consists of lowered thermal efficiency, as biomass is less energetic than the fuel originally intended in the power unit's 
design. This is mainly due to the creation of residue on heat exchange surfaces and the start of corrosion and erosion processes on those elements. Fuel with biomass admixtures is usually burnt in fluidized bed boilers. Figure 3 shows a schematic diagram of such a type of power unit [9].

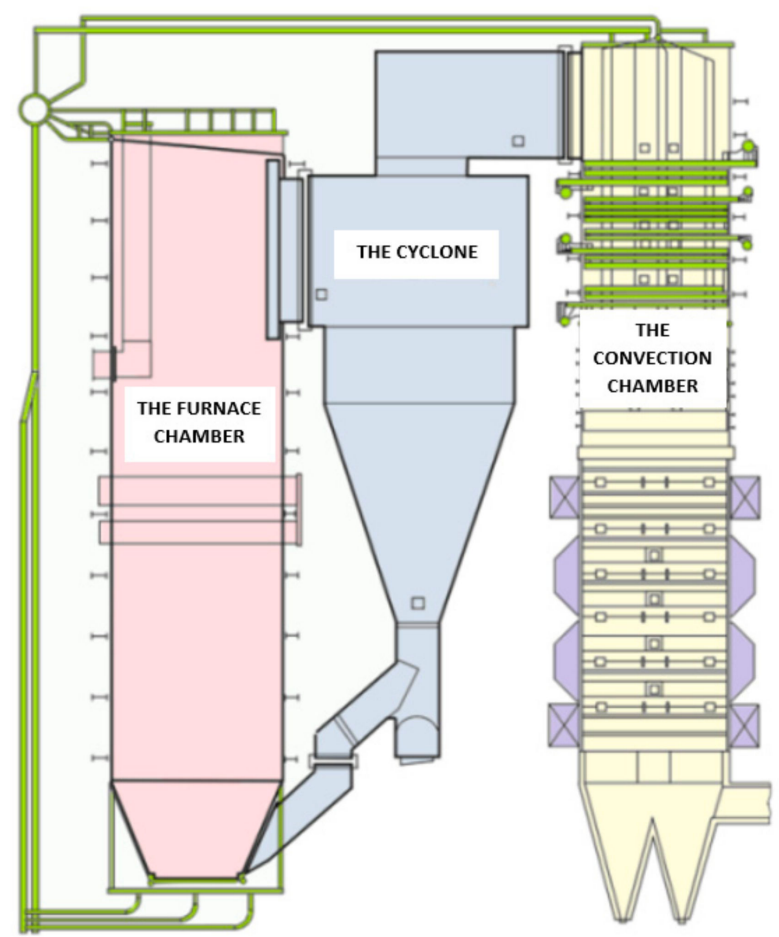

Figure 3. A scheme of fluidized bed boiler unit.

Table 1, on the other hand, shows technical parameters of a fluidized bed boiler unit.

Table 1. Operating parameters of CFB-670 boiler.

\begin{tabular}{cc}
\hline Parameter & Value \\
\hline Air excess factor l & $1.1-1.2$ \\
Temperature in the bed, Tz & $850-870{ }^{\circ} \mathrm{C}$ \\
Burnup fraction & $96-98 \%$ \\
Sulfur fixation efficiency & $90 \%$ \\
NOx emission (NOx content in flue gas) & $(\mathrm{Ca} / \mathrm{S}=1.5-2.6)$ \\
& $200-400 \mathrm{mg} / \mathrm{m}^{3}$ \\
\hline
\end{tabular}

\section{Non-Destructive Tests}

The steel structure of the power units that experienced the fire was inspected for damage. The inspections included inter alia welded joints of the unit's main components, i.e., load-bearing structure, casing of both furnace and convection chambers, cyclone, ash removal system, air ducts, and auxiliary elements. The objective was to find potential material discontinuities (fractures) and to evaluate degradation level of selected areas on boiler elements against the required standards. Where necessary (and where possible), non-destructive tests were performed by means of magnetic particle inspection with permanent magnet magnetization. In order to detect magnetic stray field, during the magnetization process, the inspected element was sprayed with magnetic particles. In order to obtain clearer MPI magnetograms, the inspected areas were degreased and painted with undercoater. The first stage consisted of a visual inspection of those external surfaces that had close contact with the fire wave. Sample results are shown in Figures 4 and 5. 
Special scrutiny was given to welded joint and bolted joint areas in the main members of the boiler's support structure [10].

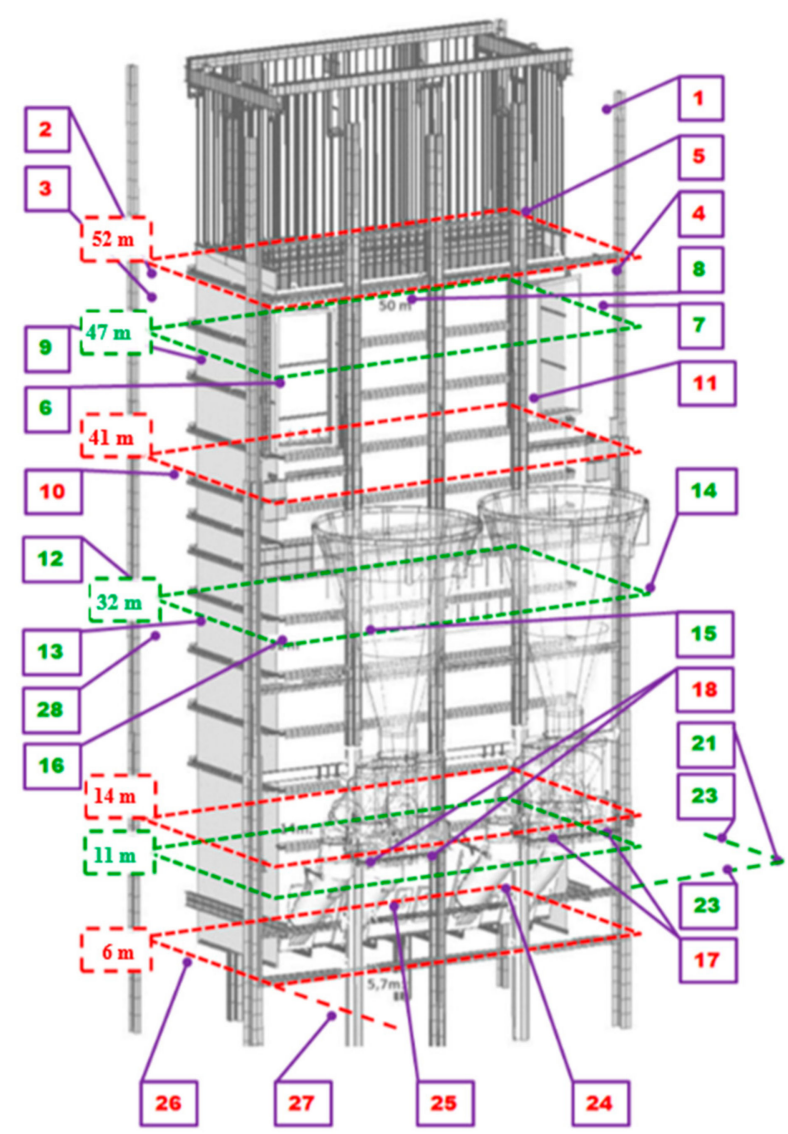

Figure 4. Diagram of the power unit showing the place and labels for inconsistencies found.

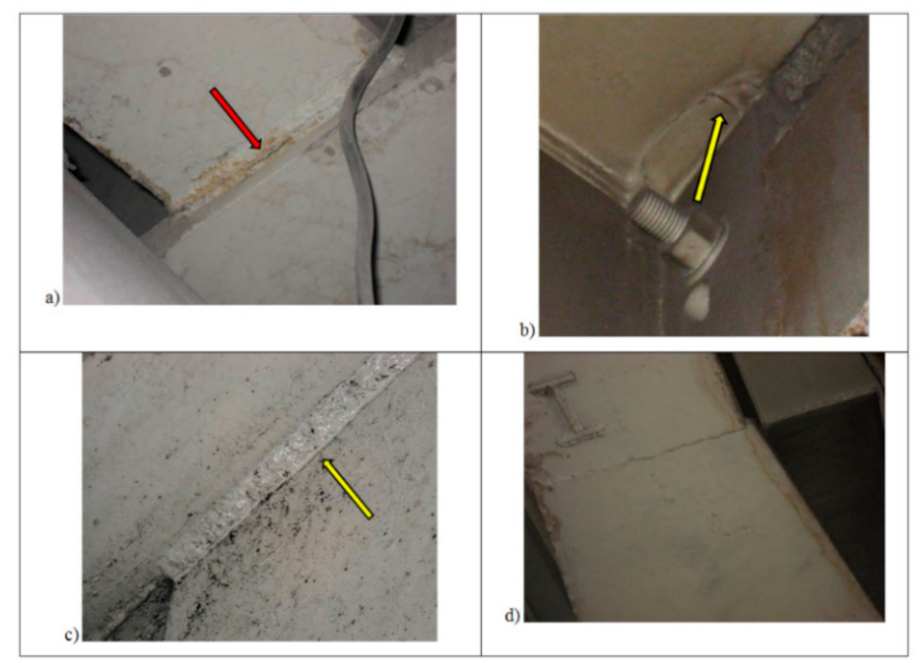

Figure 5. Weld cracks in the girders of the unit's load-bearing structure: (a) weld discontinuity between the face and the heat-affected zone (HAZ); (b) weld crack; (c) subsurface crack of the girder's weld; (d) weld crack at the connection point between load-bearing girders.

The inspected areas of the power unit were shown in Figure 4 and marked with schematic labels.

Examination of the power unit's load-bearing structure was mainly focused on the strength of load-bearing members, their connections, and joints. Inspections of load-bearing 
structure were performed on seven height levels $(6,11,12,32,41,47$, and $52 \mathrm{~m})$ indicated in Figure 4. The inspections covered welded joints and weld quality, as well as bolted joints and plastic strain of both beams and casing. The obtained results allowed to make the following observations [11]:

- $\quad$ Cracks of weld line in many places (Figure 5);

- Insufficient quality of welding and weld repairs, welded joints made in inappropriate places;

- Elastic buckling of lattice work in the load bearing structure;

- Repairs done during power unit's operation were not protected against corrosion;

- Inappropriate bracing, which may cause stress concentration in the areas of their construction;

- Additionally, a great number of welded joints is accumulated on a small area, which leads to the change in material structure, as a lot of heat is supplied and, therefore, the material loses its strength characteristics;

- Deplanation (warping) of flanges and webs in support beams, as well as deformation of reinforcing ribs in I-beam girders;

- $\quad$ Forbidden process holes (mount holes) in load-bearing girders and posts.

In order to estimate the effects of fire wave propagation from coal and biomass feeders to the boiler, control was needed of the degradation level of the boiler's loadbearing structure and of all machines within the analyzed power unit. To meet that goal, inspections of the boiler's systems and steel structure were performed. Inspection of the steel structure revealed faults that took the form of cracks in base material and between the weld and the heat affected zone, as shown in Figure 5. Much part of the structure's damage was caused by high temperature, which significantly lowered the strength of load-carrying elements to standard loads. That is when loss of stability took place. The inspection also revealed defects of the structure, caused by incorrectly performed assembly procedures and resulting in the low quality of welded joints, as well as in forbidden notches, cuts, and mount holes or process holes. The above-listed faults contributed to significantly decreased strength of the discussed elements. Additionally, geometrical notches cut in the structure (structural notches) significantly contributed to lowered durability of those elements. Apart from the above, the inspection also allowed to observe numerous signs of repairs, which had been performed during operation of the power unit and were never protected against corrosion, resulting in the appearance of numerous corrosion centers. During inspection, attention was also paid to inappropriate bracings, which may cause stress concentration in the areas of their construction. Incorrectly mounted, additional metal sheets create a structural notch, which means rapid change in stiffness, resulting in the interruption of proper load distribution. In addition, a great number of welded joints is accumulated on a small geometric area, which leads to the change in the material's structure due to great amount of heat supplied during welding. This causes the structural material to lose its strength $[12,13]$.

\section{Measurement of Vibration Levels in the Load-Bearing Structure of the Power Units}

The planned scope of research also included measurements of vibrations that occur in the combustion chamber's load-bearing (support) structure, on its individual height levels, between 5 and $50 \mathrm{~m}$. Figure 6 shows a general diagram of measurement points arrangement for the 32-m level [14].

Measurements of vibration levels were performed in two perpendicular directions on the load-carrying posts of the power unit's separate height levels. The diagram of separate measurement points, as well as the directions of the analyzed displacement and acceleration spectra are shown in Figure 7. The measurements allowed to obtain results in the form of vibration frequency characteristics for individual measurement points. Sample measurement results are shown in the following figures. Values of maximum vibration amplitudes (A) for the measured time range are given below the illustrations [14]. 


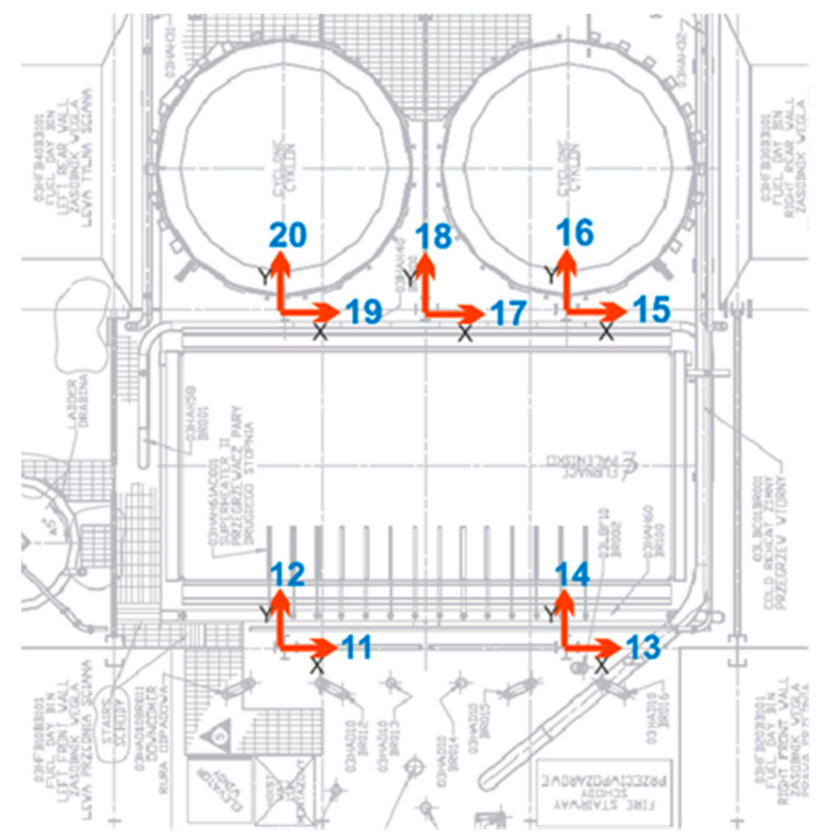

Figure 6. Diagram of measurement points on units 1, 2, and 3-the 32-m level.

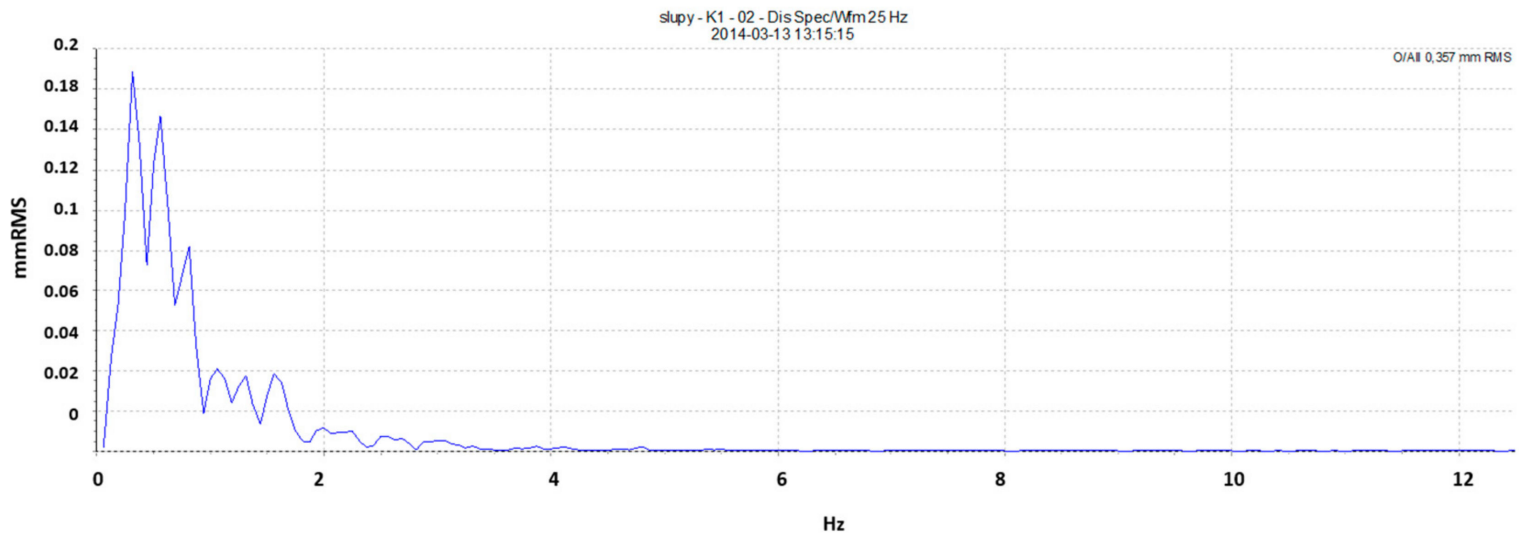

(a)

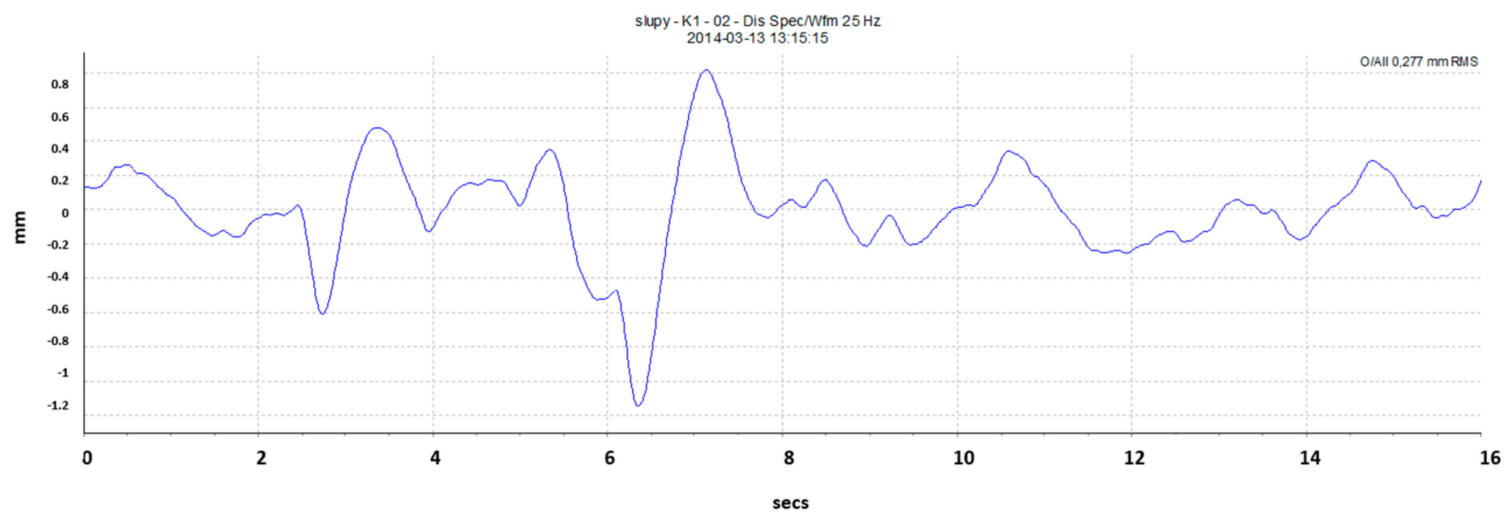

(b)

Figure 7. Diagrams of accelerations and displacements in a sample point 2 , where vibration amplitudes for the measuring range are inter alia (a) $0.815 \div 0.191$ mmRMS, (b) $-1.146 \div 1.961 \mathrm{~mm}$. 


\section{Measurements of Temperature Distribution on Particular Elements of the Power Unit}

The measurements covered heat loads of the whole power unit, including its loadbearing structure and other selected process equipment of the boiler island, and were performed using a thermal imaging camera with adequate measuring range and sensitivity. The temperature distribution, thus, obtained was used in further analysis, as one of the boundary conditions for structural strength calculations based on finite element method (FEM). Sample results of the measurements performed for the boiler's furnace chamber and auxiliary equipment are shown in Figures 8 and 9 [15].
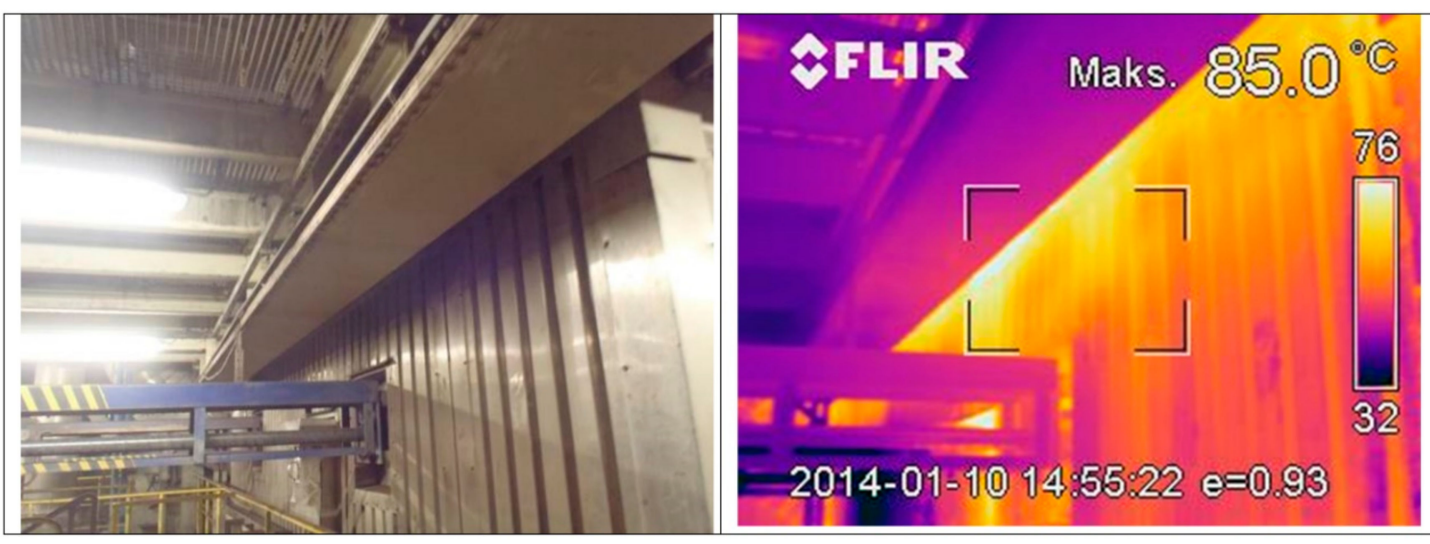

Figure 8. Temperature distribution at the soot blower entrance point into the furnace chamber.
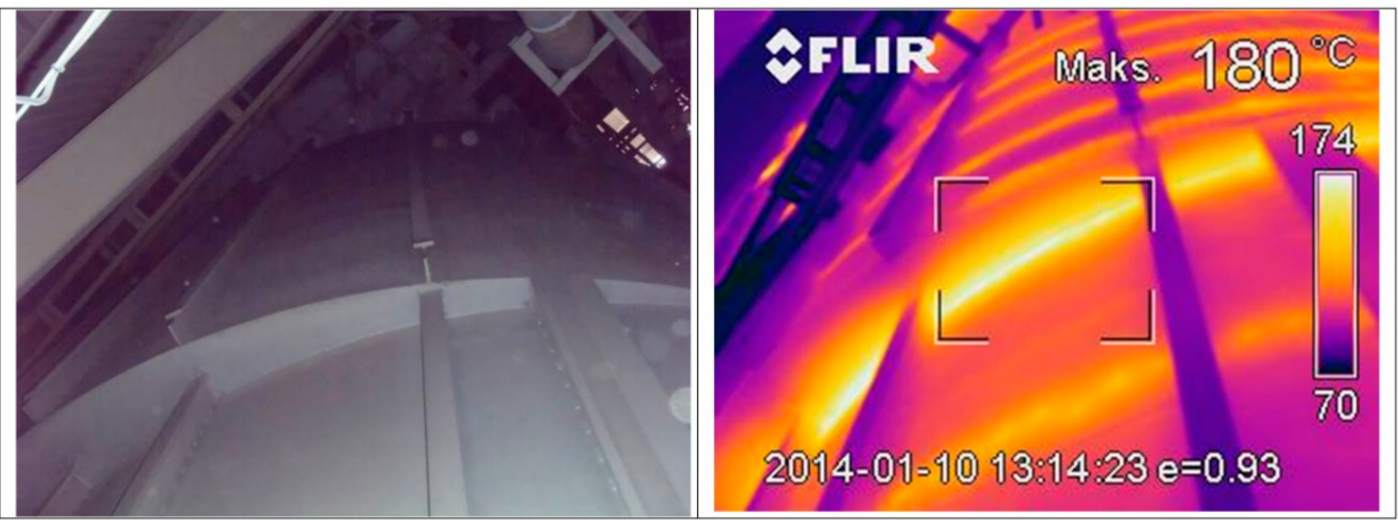

Figure 9. View of temperature distribution on the external casing of flue gas cyclone-clearly visible thermal bridges in the cyclone's upper part.

Thermal imaging inspection of temperature distribution was performed for the power unit's height levels in the range between 0 and $56 \mathrm{~m}$. In addition, the obtained thermal images allowed us to estimate the quality of thermal insulation used in the furnace chamber's external casing and other boiler equipment. This allowed us to find areas with damaged thermal insulation and the resulting thermal bridges, especially those located on the connecting points of the machines working with furnace chamber and other elements. The damage of external insulation layers was closely connected to the propagation of the fire wave in the vicinity of the power units [16].

\section{Strength Calculations for the Load-Bearing Structure of the Power Unit and Its Elements}

The measured temperature distribution was used to perform FEM strength calculations for some elements of the power units' parts, such as their load-bearing structure, cyclone, and fuel hopper. The above-listed elements were particularly subjected to heat loads resulting from the fire that occurred in the boiler hall, as they do not have insulated 
external envelope. The calculations were performed using the finite element method in the NX-IDEAS system [17]. For the sake of the calculations, geometric models of the abovementioned elements were prepared (Figure 10), which were later digitized using appropriate finite elements. The next step consisted in strength calculations, with consideration paid to local temperature changes on external surfaces of the elements [18].

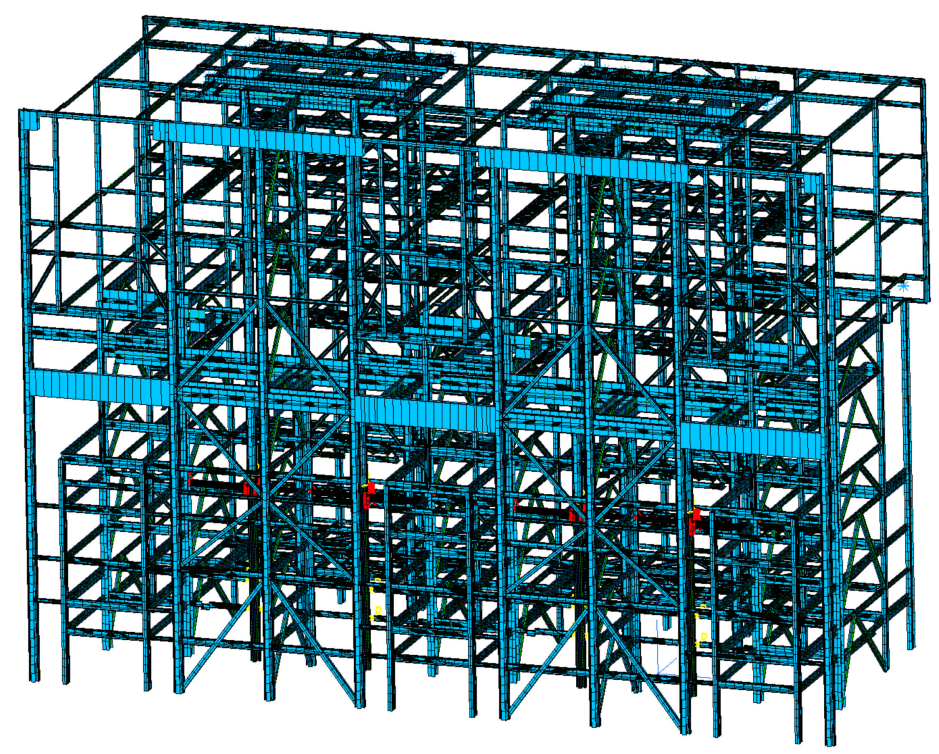

Figure 10. Load-bearing structure of the power unit-general view.

The calculations included both thermal and mechanical loads simultaneously. These are both gradients of temperature, which occur in steel structure due to its uneven heating resulting from the fire, and of structural loads, which occur due to the weight of subassemblies hung on the boiler island's steel structure. However, before the structure's effort was calculated, the spatial thermal field was found for the power unit's support structure. This kind of distribution is highly likely to occur in real structures. It is shown in Figure 11. The results of strength calculations obtained in the form of general displacement contour and Huber-Mises reduced stress contour are shown in Figure 12 [19].
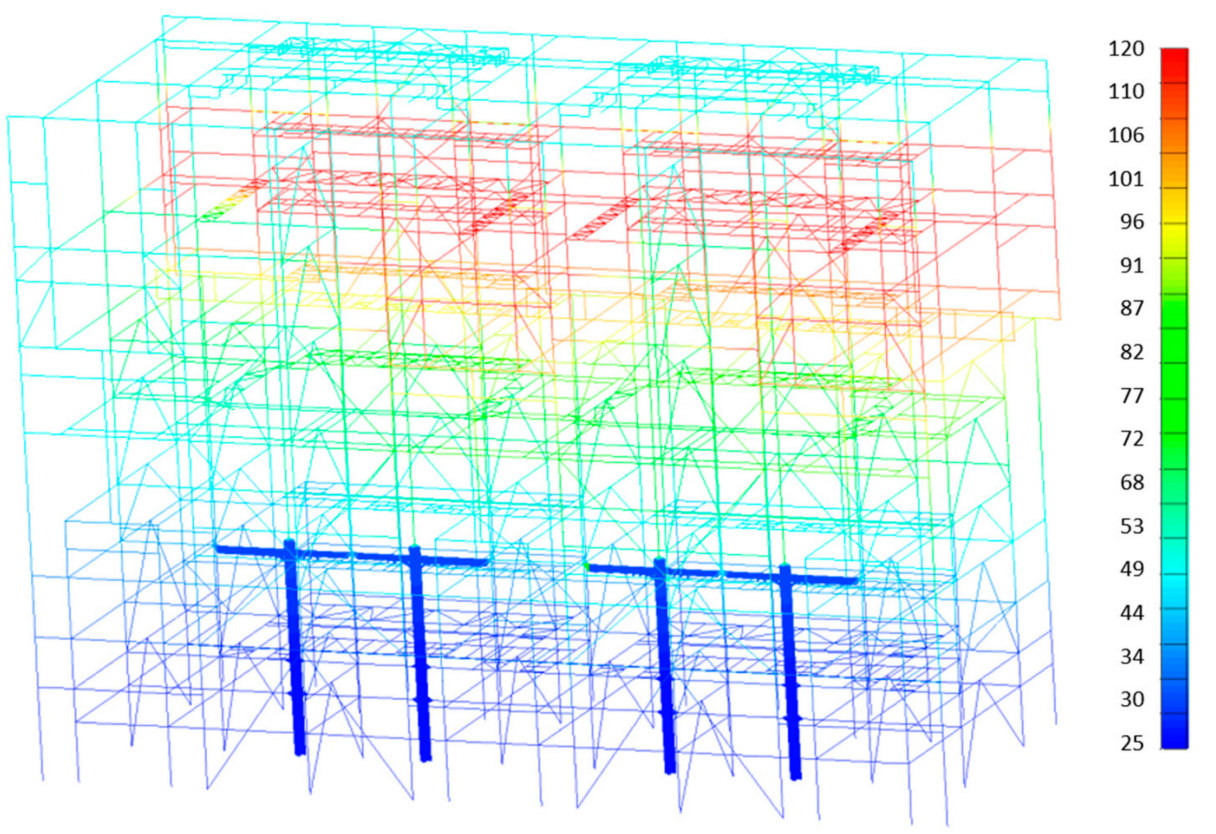

Figure 11. Thermal field contour lines $\left({ }^{\circ} \mathrm{C}\right)$ in the whole load-bearing structure of the power unit. 


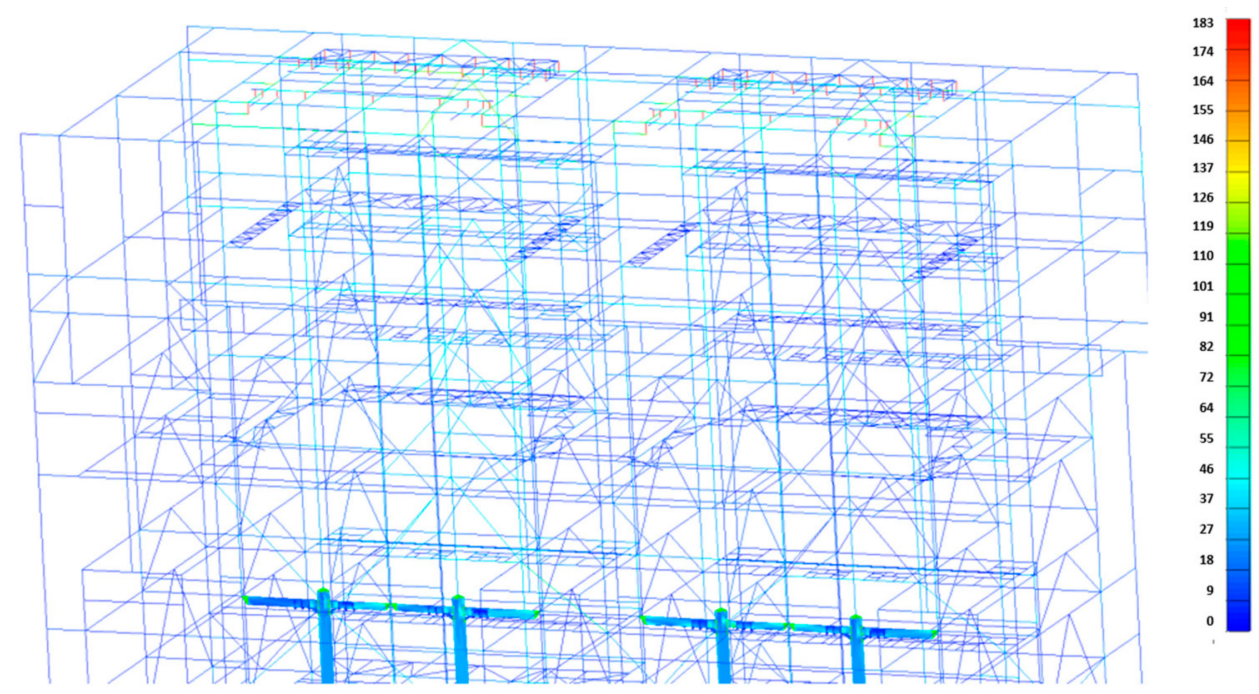

Figure 12. Huber-Mises reduced stress contour lines for the load-bearing structure of the power unit $[\mathrm{MPa}]$ - view of the upper grate area.

FEM strength calculations of the load-bearing structure showed among other things that greatest reduced stress equal to $183 \mathrm{MPa}$ could be observed in the area of the posts supporting return lines to the furnace chamber. These values are lower than the yield strength $(235 \mathrm{MPa})$ of the construction material used to build the load-bearing structure of the power units. In the remaining parts of the units' load-bearing structures, the majority of reduced stresses were approximately $50 \mathrm{MPa}$. The above data prove that the fire in the boiler hall did not cause any damage to the support structure of the power unit. FEM strength calculations were also performed for the container, by building both geometric (Figure 13) and discrete models. The container is supported in four points located in its upper part, as can be seen from the model shown in Figure 13. The colors in the model correspond to metal sheets of different thicknesses [20].

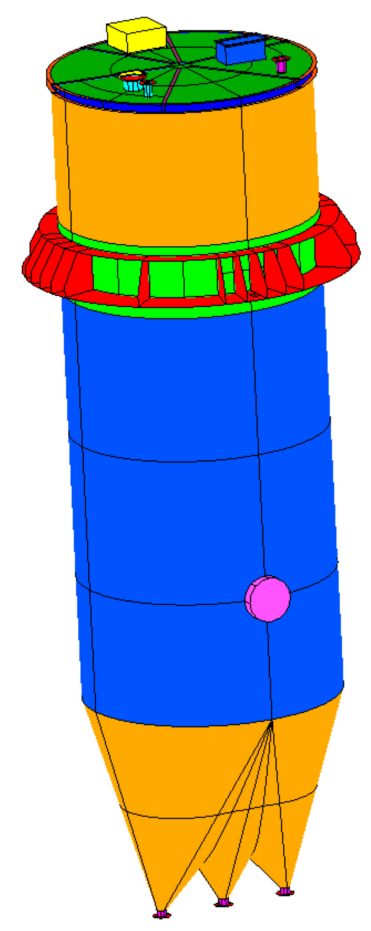

Figure 13. View of the container's complete geometric model. 
Digitization was performed using Thin Shell elements whose thickness corresponded to the thickness of metal sheets used to construct the container. The calculations included loads resulting from its normative service load and thermal gradients resulting from local exposure to heat due to the fire wave. The container was made of steel S235, which is why the following strength criteria were assumed:

$$
\sigma_{\text {red }}<\sigma_{\text {dop }}=R_{e}=230 \mathrm{MPa}
$$

where:

$\sigma_{\text {red }}$-reduced stress according to Huber and Mises [MPa];

$\sigma_{\text {dop }}$-allowable stress assumed in the analysis [MPa];

$R_{e}$-yield strength of the container structure's material [MPa].

In order to determine the reasons for the container's damage, a series of strength analyses was performed, with consideration paid to several factors that accompanied the fire and could cause a crack in the area of dumping hoppers and complete damage of the container's upper part. The rising temperature inside the boiler hall, which was the result of the fire, led to uneven heating of the boiler's surface. The thermal gradient of the boiler's casing that occurred in consequence, as well as the rise in air temperature inside the container-which translated into the rise in air pressure-both contributed to the emergence of cracks in the area of weld lines on the fuel hopper and sudden damage of its upper part that followed. Strength analysis was performed for the following air pressure values: $5 \mathrm{kPa}, 10 \mathrm{kPa}, 15 \mathrm{kPa}, \ldots$, $50 \mathrm{kPa}$ (values increased by $5 \mathrm{kPa}$ ). Impact strength of approximately $200 \mathrm{MPa}$ was assumed for the observed low quality of weld lines on the fuel hoppers. The strength analysis showed that at air pressure inside the container equal to $50 \mathrm{kPa}$ and at uneven thermal impact that occurred simultaneously, reduced stress in the area of hopper weld lines reached approximately $270 \mathrm{MPa}$ (Figure 14). This contributed to the breaking of the discussed area of the container $8 \mathrm{z}$.

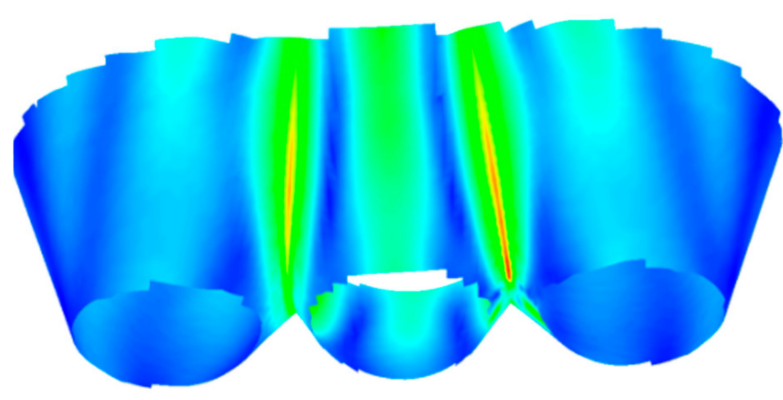

(a)

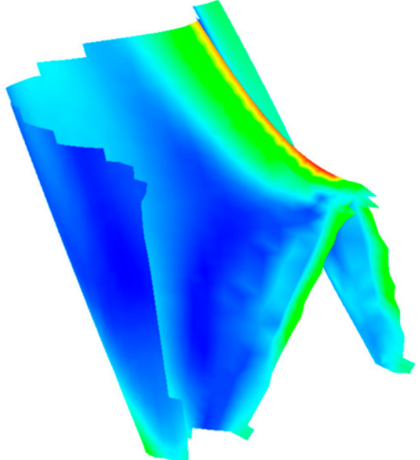

(b)

Figure 14. Reduced stress contour lines in the lower part of the container, according to Huber and Mises hypothesis [MPa] (a) hopper area of the fluidized bed material tank; (b) the hopper weld area of the fluidized bed material reservoir where the crack has occurred

At the same time, reduced stress in the container's upper part was observed at approximately $870 \mathrm{MPa}$ (Figure 15). The latter observation, along with the fact that the tests performed prove the ultimate strength of steel S235 to be at the level of $315 \mathrm{MPa}$, means that this area experienced a sudden discontinuity of the investigated object's casing [20].

The strength analysis also showed clearly that as the air pressure inside the container rose to approximately $50 \mathrm{kPa}$ and the casing heated unevenly, the casing broke in its both upper and lower parts. 


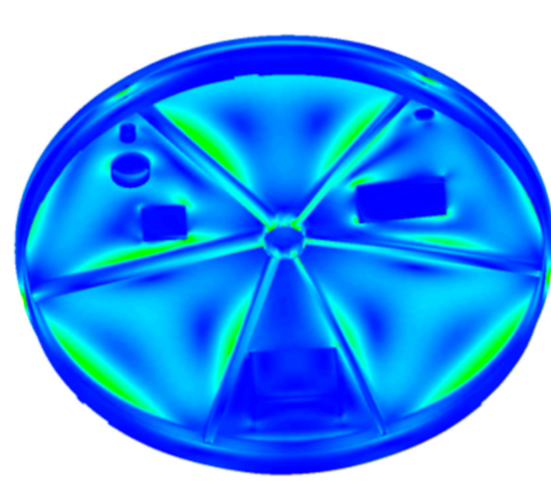

(a)

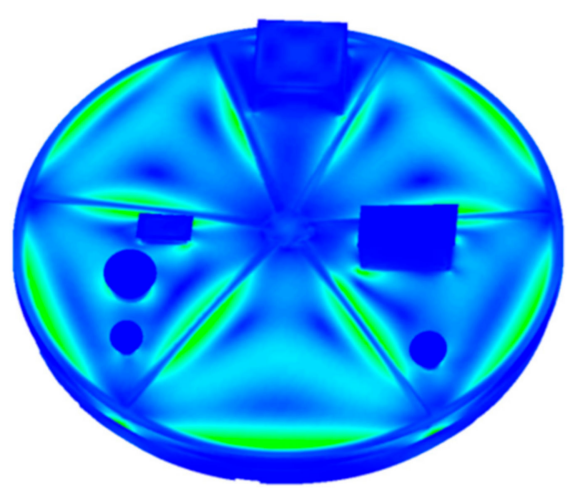

(b)

Figure 15. Reduced stress contour lines in the upper part of the container, according to Huber and Mises hypothesis [MPa]: (a) Calculation results of the upper cover of the bed material tank from the outside, (b) Calculation results of the upper cover of the bed material tank from the inside.

\section{Summary and Conclusions}

Measurement results allowed to estimate the effects of the fire wave that passed through a power station. The works were divided into several stages:

- Investigation of the damage that the passing fire wave caused to the load-bearing structure of the power unit's elements, together with the equipment located in the technological line. As a parallel task, on-site inspections included the power unit's main elements that remained in service for many years.

- $\quad$ Problematic or damaged main elements found during inspection allowed us to estimate the technical condition of the investigated structure and to establish the scope of necessary repair works.

- Inspections of welded joints were performed only in available places, on the unit's main elements, i.e., on the load-bearing structure, second pass chamber, cyclone, ash removal system, air ducts, auxiliary elements, etc. As indicated in the article, much attention was paid to the levels on which the fire wave passed.

The passing fire wave caused greatest damage in front of the unit, at the coal and biomass supply galleries. Coal and biomass ignition in the space between the units generated soot, which combined with ash and water was used to extinguish the fire and produced compressed mass (Figure 14). The mass had the consistency of concrete and covered electric wires placed in conduits. The wires that were laid in conduits close to each other stopped the flowing mass, which set shortly. This phenomenon was observed only on the $6 \mathrm{~m}$ level of the power unit [20].

Author Contributions: Conceptualization, M.P.; methodology, A.G.; software, M.P. validation, M.P.; formal analysis, A.G., M.P.; investigation, A.G.; resources, A.G.; data curation M.P.; writing—original draft preparation, A.G., M.P.; writing—review and editing, M.P.; visualization A.G., M.P.; supervision, A.G.; project administration, A.G.; funding acquisition, A.G. All authors have read and agreed to the published version of the manuscript.

Funding: This research received no external funding.

Data Availability Statement: The data presented in this study are available on request from the corresponding author. The data are not publicly available due to provisions in the contract with the company for which the research was carried out.

Acknowledgments: As part of the work carried out, no support was provided, either from external persons or institutions.

Conflicts of Interest: The authors declare no conflict of interest. 


\section{References}

1. Schröder-Hinrichs, J.U.; Baldauf, M.; Ghirxi, K.T. Accident investigation reporting deficiencies related to organizational factors in machinery space fires and explosions. Accid. Anal. Prev. 2011, 43, 1187-1196. [CrossRef] [PubMed]

2. Zhu, Y.; Wang, D.; Shao, Z.; Xu, C.; Zhu, X.; Qi, X.; Liu, F. A statistical analysis of coalmine fires and explosions in China. Process Saf. Environ. Prot. 2019, 121, 357-366. [CrossRef]

3. Czmochowski, J.; Górski, A.; Iluk, A.; Wyszyński, J. Numeryczna weryfikacja wytężenia przegrzewacza grodziowego kotła energetycznego. Syst. J. Transdiscip. Syst. Sci. 2002, 7, 105-112.

4. Czmochowski, J.; Górski, A.; Paduchowicz, M.; Rusiński, E. Diagnostic method of measuring hanger rods tension forces in the suspension of the power boilers combustion chamber. J. Vibroeng. 2012, 14, 129-134.

5. Kowalczyk, M.; Czmochowski, J.; Derlukiewicz, D. Diagnostic Models of the States of Developing Fault for Working Parts of the Excavator. Solid State Phenom. 2010, 165, 285-289. [CrossRef]

6. Li, L.; Qin, B.; Ma, D.; Zhuo, H.; Liang, H.; Gao, A. Unique spatial methane distribution caused by spontaneous coal combustion in coal mine goafs: An experimental study. Process Saf. Environ. Prot. 2018, 116, 199-207. [CrossRef]

7. Mi, C.; Li, W.; Xiao, X.; Berto, F. An energy-based approach for fatigue life estimation of welded joints without residual stress through thermal-graphic measurement. Appl. Sci. 2019, 9, 397. [CrossRef]

8. Coimbra, R.N.; Escapa, C.; Otero, M. Comparative thermogravimetric assessment on the combustion of coal, microalgae biomass and their blend. Energies 2019, 12, 2962. [CrossRef]

9. Zhou, C.; Gao, F.; Yu, Y.; Zhang, W.; Liu, G. Effects of Gaseous Agents on Trace Element Emission Behavior during Co-combustion of Coal with Biomass. Energy Fuels 2020, 34, 3843-3849. [CrossRef]

10. Krolczyk, J.B.; Gapiński, B.; Krolczyk, G.M.; Samardžić, I.; Maruda, R.W.; Soucek, K.; Legutko, S.; Nieslony, P.; Javadi, Y.; Stas, L. Topographic inspection as a method of weld joint diagnostic. Teh. Vjesn. 2016, 23, 301-306. [CrossRef]

11. Landowski, M.; Świerczyńska, A.; Rogalski, G.; Fydrych, D. Autogenous fiber laser welding of 316L austenitic and 2304 lean duplex stainless steels. Materials 2020, 13, 2930. [CrossRef] [PubMed]

12. Górka, J.; Stano, S. Microstructure and properties of hybrid laser arc welded joints (laser beam-MAG) in thermo-mechanical control processed S700MC steel. Metals 2018, 8, 132. [CrossRef]

13. Tabatabaeipour, M.; Hettler, J.; Delrue, S.; Van Den Abeele, K. Non-destructive ultrasonic examination of root defects in friction stir welded butt-joints. NDT E Int. 2016, 80, 23-34. [CrossRef]

14. Vibrations, N.M.; Bergamo, E.; Fasan, M. Efficiency of Coupled Experimental-Numerical Predictive Analyses for Inter-Story Floors Under Non-Isolated Machine-Induced Vibrations. Actuators 2020, 9, 87.

15. Shittu, S.; Li, G.; Zhao, X.; Akhlaghi, Y.G.; Ma, X.; Yu, M. Comparative study of a concentrated photovoltaic-thermoelectric system with and without flat plate heat pipe. Energy Convers. Manag. 2019, 193, 1-14. [CrossRef]

16. Ren, K.; Chew, Y.; Zhang, Y.F.; Bi, G.J.; Fuh, J.Y.H. Thermal analyses for optimal scanning pattern evaluation in laser aided additive manufacturing. J. Mater. Process. Technol. 2019, 271, 178-188. [CrossRef]

17. NX-Ideas. Producer: Siemens PLM Software, Distributor: ATA ENGINEERING INC. Available online: https://www.ataplmsoftware.com/ (accessed on 22 February 2021).

18. Doronin, S.V.; Reizmunt, E.M. Multi-Model Interval Estimators of the Strength State of Structurally Complex Load-Bearing Units of Production Equipment. Chem. Pet. Eng. 2018, 53, 604-609. [CrossRef]

19. Ortlepp, R.; Ortlepp, S. Textile reinforced concrete for strengthening of RC columns: A contribution to resource conservation through the preservation of structures. Constr. Build. Mater. 2017, 132, 150-160. [CrossRef]

20. Liu, J.; Xu, T.; Guo, Y.; Wang, X.; Frank Chen, Y. Behavior of circular CFRP-steel composite tubed high-strength concrete columns under axial compression. Compos. Struct. 2019, 211, 596-609. [CrossRef] 